\title{
La articulación de Castilla y España como tema de la canción popular ${ }^{1}$
}

\author{
The Articulation of Castile and Spain \\ as a Subject of the Popular Song
}

\author{
Carlos Alberto Camazón Linacero \\ CPEIP "Santiago Apóstol". \\ Calzada de los Molinos, Palencia
}

\section{RESUMEN}

¿Es Castilla la "madre" de España o una "Víctima" de ella? Este artículo no pretende responder a semejante pregunta, sino analizar el discurso de un conjunto de canciones populares que han desarrollado esos y otros tópicos en torno a la relación de Castilla con España, vinculando ese discurso al contexto en el que tales canciones han sido producidas y reproducidas. Se sostiene que esas composiciones son deudoras de los debates que los eruditos han mantenido sobre la articulación de ambas patrias y que la difusión de dichas canciones ha contribuido a que agentes ajenos a la intelectualidad adopten como suyas las ideas provenientes de esos debates y las incluyan en sus prácticas de identificación y diferenciación.

Palabras clave: Castilla, España, Patria, Prácticas de identificación y diferenciación, Canción popular.

\section{SUMMARY}

Is Castile the "mother" of Spain, or its "victim"? The purpose of this article is not to respond to such a question but to analyze the discourse of a group of popular songs which have developed those clichés, as well as others, about the relationship between Castile and Spain. It also aims to connect the aforementioned discourse with the context in which those songs have been produced and reproduced. According to the writer, those compositions are indebted to the debates conducted by scholars about the articulation of both homelands. He asserts that their diffusion has contributed to the adoption by agents alien to the intelligentsia of the ideas therein originated, thus including them in their identification and differentiation practices.

Key words: Castile, Spain, Homeland, Identification and Differentiation Practices, Popular Song.

Los antropólogos y etnomusicólogos que se han interesado por Castilla no han prestado demasiada atención en sus etnografías y ensayos a las canciones que nos hablan de ella, probablemente porque estas no pertenecen, en la mayoría de los ca-

\footnotetext{
${ }^{1}$ Agradezco al profesor Ángel Díaz de Rada el tiempo que ha dedicado a leer y debatir conmigo este artículo.
} 
sos, al cancionero tradicional. Pero los cantos que tematizan patrias y pueblos ${ }^{2}$ - sean cuales sean su procedencia y su autoría- y sus contextos de producción y reproducción exigen descripción y análisis cuando se presentan en el campo etnográfico de una investigación que pretende aportar alguna luz sobre los procesos de identificación y diferenciación de los agentes sociales.

No parece que la priorización de la búsqueda de rasgos objetivos que constituyan "identidades culturales" (músicas tradicionales entre ellos), con el sesgo esencialista que ello suele conllevar, facilite demasiado la comprensión de la naturaleza de dichos procesos, pues, como ha demostrado Ángel Díaz de Rada, “una cultura no está acotada en las fronteras de ningún grupo humano. Una cultura no es independiente de otras culturas, ni puede serlo" (2010: 247). Miguel de Unamuno ya se topó con el problema hace más de un siglo, cuando disertaba sobre el "casticismo español", al percatarse, a medida que avanzaba en sus pesquisas, de "lo descabellado del empeño de discernir en un pueblo o en una cultura, en formación siempre, lo nativo de lo adventicio" (1986 [1902]: 125). Por eso, en este tipo de investigaciones, conviene orientar la atención hacia las prácticas dialógicas con las que los agentes, de acuerdo con sus predicados de origen, dan forma y significado a los límites étnicos y patrios que aplican en su acción social, a los rasgos diferenciales subjetivos que exhiben y a sus relaciones con miembros de otros grupos (Cf., por ejemplo, Barth 1976 [1969]; Baumann y Gingrich 2004; Díaz de Rada 2008). Componer, interpretar, divulgar y escuchar canciones que tematicen pueblos y patrias, así como el discurso del que son portadoras, forma parte del repertorio de tales prácticas.

Una excepción a la desatención a la que me refería al principio la encontramos - aunque fuera de la antropología y la etnomusicología - en la obra de Fernando González Lucini, que hace un intento de catalogación de canciones grabadas entre 1963 y 1983 que tratan de "la realidad humana" y "la historia concreta de nuestros pueblos" de España (1989 [1984]: 404-418). En el apartado dedicado a Castilla, se refiere a diez canciones sueltas y un disco completo. Sin embargo, no están inventariadas todas las susceptibles de serlo que se grabaron en ese periodo de tiempo, a las que, además, habría que sumar las anteriores a 1963 y las posteriores a 1983 para hacernos una idea del alcance del tema en la música cantada. Por la discografía que he podido consultar ${ }^{3}$, la cual no considero exhaustiva, resulta que desde los años veinte

\footnotetext{
${ }^{2}$ Considero que una canción tematiza una patria o un pueblo cuando toma un crono-topónimo (España, Castella o Burgos) o un etnónimo ("berciano", "asturianu" o "gitano") como eje principal o destacado de su discurso y desarrolla alguna idea relativa a su configuración espaciotemporal y sociocultural, o a su articulación con otras categorías de esos mismos tipos.

3 Las grabaciones consultadas provienen, principalmente, de tres fondos: el de la red de bibliotecas de Castilla y León, el del Centro Etnográfico de la Fundación Joaquín Díaz y el mío personal. Para guiarme en la búsqueda de canciones sobre Castilla y los "castellanos", partí de mi conocimiento previo acerca de compositores e intérpretes que habían trabajado sobre el tema, información que fui ampliando gracias al citado libro de González Lucini (1989 [1984]) y a las conversaciones y entrevistas con algunos de mis informantes, como el exmilitante de Unión Castellanista Antonio Campoo o la cantautora Amparo García Otero. También fueron de gran ayuda las sugerencias de Carlos Porro, encargado de la fonoteca de la Fundación Joaquín Díaz. Por otro lado, fue muy útil el análisis sistemático en Internet de foros castellanistas y páginas web de formaciones y partidos políticos operativos en el campo que investigaba, en las que se colgaban y recomendaban canciones, y se vendían cedés de grupos relacionados con el tema.
} 
del siglo pasado hasta hoy se habrían editado más de medio centenar de pistas sueltas y, al menos, cuatro discos completos cantados tematizando Castilla, la mayoría de las veces —-salvo notables excepciones- por compañías discográficas pequeñas o independientes y, más recientemente, por los propios autores-intérpretes (autoedición).

A lo largo de la investigación que he llevado a cabo en la Comunidad Autónoma de Castilla y León ${ }^{4}$, he podido comprobar que muchas de esas canciones, interpretadas y reproducidas públicamente en actividades educativas escolares y extraescolares, conciertos, medios de comunicación y actos políticos o politizados, han procurado contribuir - con mayor o menor éxito- a la difusión y afianzamiento de las ideas que la intelectualidad ha elaborado sobre Castilla en general ${ }^{5}$, y sobre la relación de esta con España en concreto.

\section{LA ARTICULACIÓN DE CASTILLA Y ESPAÑA EN LAS PRÁCTICAS DE IDENTIFICA- CIÓN "CASTELLANA"}

\section{MODELOS OPUESTOS}

Soleada mañana en la pequeña localidad de Villalar de los Comuneros. Es 23 de abril de 2009, efeméride de la gran derrota comunera ocurrida en la campiña de este pueblo en 1521. Se está celebrando, como cada año desde 1986, la Fiesta de la Comunidad Autónoma de Castilla y León, aunque muchos "castellanos" y castellanistas vienen hasta aquí para festejar a Castilla.

Estoy en la plaza del pueblo, frente al obelisco comúnmente llamado "el monolito", que fue levantado en 1889 en memoria de los cabecillas de las Comunidades de Castilla. El recientemente creado Partido Castellano (PCAS) está rindiéndoles homenaje. En este momento interviene Pedro Arias, cabeza de Candidatura Independiente-

\footnotetext{
${ }^{4}$ Entre enero y julio de 2009 realicé trabajo de campo para estudiar cómo se forjaban y manifestaban en los "castellanos y leoneses" las prácticas de identificación vinculadas a esa patria emergente que es la Comunidad Autónoma de Castilla y León. La parte fundamental de la observación participante la realicé en el colegio en el que estaba destinado, ubicado en Guardo (Palencia), y en Villalar de los Comuneros (Valladolid), donde se concentra la celebración del día de Castilla y León. El trabajo de campo se extendió a otros pueblos y ciudades de Palencia, León, Zamora, Segovia, Burgos y Valladolid, realizando entrevistas programadas y observación participante de acontecimientos relacionados con mi objeto de estudio. Una parte de los resultados del análisis de los cuadernos de campo la utilicé para la confección del trabajo de investigación que, bajo la dirección de Ángel Díaz de Rada y con el título "Castellanos y ¿leoneses?" por un día. Una aproximación etnográfica a la burocratización de los procesos de identificación en el orden etnonacional, presenté en el programa de doctorado del Departamento de Antropología Social y Cultural de la Facultad de Filosofía de la UNED. El argumento del texto enfocaba la fiesta oficial de Castilla y León y su repercusión en el trabajo escolar. Una vez obtenido el Diploma de Estudios Avanzados en enero de 2010, continué con el trabajo de campo hasta octubre de 2011, desplazando en septiembre de 2010 el punto principal de observación a mi nuevo destino profesional en Calzada de los Molinos (Palencia) y ampliando el campo a lugares periféricos como Treviño.

${ }^{5}$ Quizás el ejemplo más notable de este fenómeno sea la musicalización, por parte del grupo Nuevo Mester de Juglaría (1976), de extensos fragmentos del romance Los comuneros (López Álvarez 1972), que no solo ha vehiculado una teoría de Castilla, sino que se ha convertido, en sí misma, en una praxis de castellanismo.
} 
El Partido de Castilla y León (CI-PCYL) ${ }^{6}$, a la sazón integrada en dicha agrupación castellanista. Al terminar su discurso, dice desde el monumento: "Muchas gracias [a] todos por venir; y viva Castilla y León, viva España y el Partido de Castilla y León ${ }^{7}$; adelante todos juntos. ¡Gracias!».

Junto a mí, un joven ha estado escuchando el discurso atentamente. Lleva prendida de los hombros, a modo de capa, una bandera morada con estrella roja de cinco puntas en el centro y, sobre ella, un castillo amarillo ${ }^{8}$. Es la adaptación del "pendón comunero" ${ }^{9}$ que emplean los militantes y simpatizantes de las agrupaciones que propugnan una república socialista para una Castilla soberana compuesta por las diecisiete provincias cuyos representantes firmaron el Pacto Federal Castellano en $1869^{10}$. A menudo, ellos mismos se refieren a ese marco común de ideología y acción políticas con el nombre de "movimiento popular castellano". Izquierda Castellana (IzCa), la más destacada de las organizaciones que lo integran, describió ese pendón estrellado como su bandera en el Registro de Partidos Políticos del Ministerio del Interior.

Al escuchar los "vivas" del orador, el chico le dice indignado a su compañero: "¿Cómo que viva España? Eso ha sonado muy mal" "11.

Han transcurrido cinco meses, y ahora paseo por el pueblo vitivinícola de Cigales, cercano a Valladolid. Sobre el revocado de cemento de las tapias que delimitan unos solares urbanos aún sin edificar, hay dos pintadas azules escritas con mayúsculas y firmadas por Falange Española de las JONS: "ESPAÑA UNA / SOLA NACIÓN" y "POR CASTILLA / POR ESPAÑA" (fig. 1).

\footnotetext{
${ }^{6}$ Nombre y siglas con las que se presentó a las elecciones municipales y autonómicas de 2007.

${ }^{7}$ Partido de Castilla y León (PCAL) era la marca del PCAS para dicha Comunidad Autónoma, según el artículo $3^{\circ}$ de sus estatutos. Pero el partido de Pedro Arias, desvinculándose del PCASPCAL, presentó sus propias listas en las elecciones autonómicas y municipales de mayo de 2011 con el nombre de El Partido de Castilla y León-Candidatura Independiente (PCAL-CI), generando así una confusión de nombres y siglas que tuvo como consecuencia la adopción, por parte de la agrupación castellanista, de una sola marca (PCAS) para Castilla y León, Madrid y CastillaLa Mancha. La decisión, que se tomó en el II Congreso Nacional del Partido Castellano celebrado en Segovia el 8 de octubre de 2011, no gustó a muchos afiliados y cargos electos de Burgos, Valladolid y Palencia, que denunciaron, además, la deriva nacionalista del PCAS, por lo que siguieron empleando la marca PCAL. Los descontentos han terminado escindiéndose y formando el Partido Regionalista de Castilla y León (PRCAL, inscrito en el Registro de Partidos Políticos del Ministerio del Interior el 16 de marzo de 2012), al que se han unido también cargos electos del PCAL-CI.

${ }^{8}$ En este contexto, la interpretación de tales símbolos sería la siguiente: el morado representa a los comuneros; la estrella roja de cinco puntas, el socialismo internacionalista, y el castillo amarillo, Castilla.

9 Castillo dorado sobre fondo morado, sin estrella roja. Aunque habría mucho que precisar sobre los significados y usos que las diferentes tendencias castellanistas han dado a cada uno de ellos, podemos afirmar que este pendón y el "castellano" (castillo dorado sobre fondo carmesí) son los emblemas básicos del castellanismo. Esto hace que el PCAS, por ejemplo, los emplee indistintamente, si bien se percibe una cierta preferencia por el pendón morado.

${ }^{10}$ Albacete, Ávila, Burgos, Ciudad Real, Cuenca, Guadalajara, León, Logroño, Madrid, Palencia, Salamanca, Santander, Segovia, Soria, Toledo, Valladolid y Zamora.

${ }^{11}$ El colofón del discurso de Pedro Arias aún se recordaba un año después. Como el 23 de abril de 2010 terminara su intervención desde "el monolito" sin proferir un "viva España", una voz burlona se alzó de entre un grupo de jóvenes portadores del pendón estrellado, que escuchaba sus palabras, para refrescarle la memoria: «Viva España: se te ha olvidado!».
} 


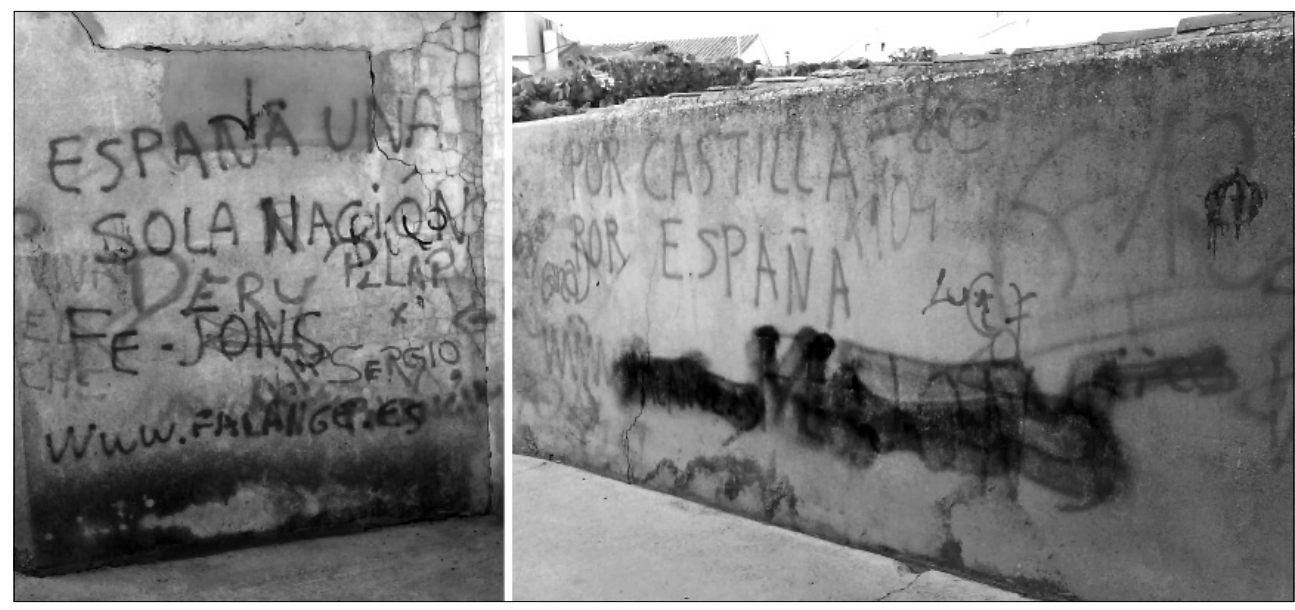

FIGURA 1.-Pintadas firmadas por FE-JONS en Cigales (Valladolid).

FE de las JONS siempre ha dejado clara su oposición al proceso autonómico de España porque lo considera un detonante del resquebrajamiento de la "unidad nacional", así que resultaría paradójico imaginarse al autor de los anteriores grafitos participando en los actos de la Fiesta de la Comunidad Autónoma de Castilla y León o, más aún, en los del "día nacional de Castilla", que es como denominan los nacionalistas "castellanos" el 23 de abril. Pero ello no implica, como podemos comprobar, que renuncie al cronotopo Castilla en sus prácticas de identificación patria, aunque su manera incluyente de articular Castilla con España sea radicalmente contraria a la oponible del joven castellanista de Villalar.

Estos ejemplos representan los dos extremos de la gama de modelos de articulación entre ambas patrias que manejan los nativos en su acción social. El quid diferencial de cada uno de ellos viene determinado, en gran parte, por el papel que asignan a Castilla y a "lo castellano" en la construcción de España y de "lo español". Los discursos que afirman, niegan o matizan la manida proposición Castilla ha becho España ${ }^{12}$ y su corolario Castilla es el centro de España ${ }^{13}$ son constructos eruditos elaborados en diversos contextos académicos e ideológicos. No obstante, esos discursos han transcendido el ámbito erudito para anclarse en las prácticas de identificación patria de quienes se predican "castellanos", la mayoría de las veces en versiones muy simplificadas. Las instituciones políticas y administrativas juegan un papel decisivo en ese trasvase de ideas, que se canaliza, en buena medida, a través de la educación (esco-

\footnotetext{
12 "Castilla ha hecho la nación española" (Unamuno 1986 [1902]: 48); "España es una cosa hecha por Castilla" (Ortega y Gasset 1977 [1921]: 48); "Castilla hizo a España" (Sánchez Albornoz 1977 [1973]: 116).

${ }^{13}$ Un ejemplo de tal afirmación son estos versos del poema juvenil de Joan Maragall (18601911) "Or de llei", inédito en vida: "El nostre temps era finit / i el de Castella començava: / el cos Espanya es nomenava / pèro Castella era l'esprît" (1984: 279). A la identificación de Castilla con el poder central se oponen, entre otros, Claudio Sánchez Albornoz (1977 [1973]: 114) y Julián Marías (1977: 241).
} 
lar y extraescolar), la comunicación mediática o la acción política, esta última evidenciada en los anteriores ejemplos.

\section{CANTARES OPUESTOS}

Pero volvamos ahora junto al joven castellanista de Villalar. Me fijo en la botella que lleva bajo el brazo. Tal vez contenga refresco; quizás, calimocho o cubata. Barrunto que, como tantos otros asistentes, ha estado por la noche celebrando el "día nacional de Castilla", y que aún no se ha acostado. Me le imagino en los conciertos de Descargando Bidones, Electropelvis y Sin Arreglo celebrados en la carpa que IzCa ha montado para el evento en las eras del pueblo ("la campa"). Como está justo al lado de aquella, puede que se haya pasado también por la carpa del colectivo Resaca Castellana (RC), formado por hinchas castellanistas y antifascistas del Burgos Fútbol Club, para ver la actuación de Duff Hooligans. Los miembros de esta banda están vinculados a IzCa y a Segovirras (hinchas de la Gimnástica Segoviana), que, como RC, se integra en la asociación agonística Hinchas Castilla, aglutinante de diferentes hinchadas castellanistas y antifascistas peticionarias de selecciones deportivas "castellanas".

Allí, en la carpa de RC, el joven habrá oído a los Duff Hooligans su "Castilla comunera"; y aquí, en "el monolito", al escuchar ese "viva España" de Pedro Arias, habrá resonado en su cabeza esta estrofa de la canción:
Un pueblo que lucha por volverse a levantar como en 1521 volveremos a luchar, el yugo español que oprime nuestra nación con hoces y martillos será destruido sin ninguna compasión ${ }^{14}$.

O esta otra:
No nos identificamos con el estado español genocida de un continente desde 1492, no nos identificamos con el estado español heredero del franquismo camuflado en constitución ${ }^{15}$.

Tiempo después, al leer en Cigales las pintadas firmadas por FE de las JONS, que también incluyen la dirección de su página web (www.falange.es), me pregunto si su autor escuchará y entonará canciones que expresen su manera de articular Castilla y España. Como Internet se ha convertido en el escaparate ideológico y en el tablón de anuncios de las agrupaciones políticas minoritarias, decido echar un vistazo a la página web de Falange. En ella hay un enlace a una tienda virtual (www.tiendafalangista.es) en la que encuentro un cedé titulado Cancionero inédito del Frente de Juventudes. Una de sus canciones, "Los muchachos de Castilla", que rememora la participación de los

\footnotetext{
${ }^{14}$ Duff Hooligans 2007: "Castilla Comunera". (Las referencias de las citas de letras de canciones — que indican intérprete, año de edición de la grabación y título de la canción- remiten al lector a la discografía que aparece al final del artículo).

15 Ibid.
} 
falangistas "Castellanos" en la batalla del Alto del León durante la Guerra Civil, parece querer responder a mi pregunta:

$$
\begin{aligned}
& \text { En el Alto del León, } \\
& \text { hizo Castilla una hazaña } \\
& \text { que la cantan las estrellas } \\
& \text { a las madres apenadas }{ }^{16} \text {. }
\end{aligned}
$$

La hazaña se produjo, claro está, por España:

$$
\begin{aligned}
& \text { Toda la cuesta está roja } \\
& \text { de sangre y de flechas santas, } \\
& \text { pero conquistó la cumbre } \\
& \text { la bandera roja y gualda }{ }^{17} \text {. }
\end{aligned}
$$

Con el tiempo, el análisis de una extensa discografía comercial me permitirá descubrir que la articulación de Castilla y España no es un tema que se agote en las dos canciones mencionadas hasta ahora. Exaltar la españolidad de Castilla, matizarla para acabar con el sambenito del centralismo "castellano" o negarla abiertamente han sido, como veremos a continuación, cuestiones más presentes en la canción popular de lo que podría parecer en un principio.

\section{LA ARTICULACIÓN DE CASTILLA Y ESPAÑA EN LA CANCIÓN POPULAR}

\section{"CASTILLA, MADRE DE ESPAÑA"}

Un ejemplo más que evidente de la afirmación de Castilla como origen, centro y sinécdoque de España lo encontramos en esta redondilla:

$$
\begin{aligned}
& \text { Te quiero, tierra bravía, } \\
& \text { y adoro en ti a toda España, } \\
& \text { porque tu suelo es la entraña } \\
& \text { de la madre patria mía }{ }^{18} \text {. }
\end{aligned}
$$

Pertenece al "Canto a Castilla" de la zarzuela La pastorela, con un libreto de Fernando Luque y Enrique Calonge (1927) al que pusieron música los maestros Pablo Luna y Federico Moreno Torroba, estrenada con gran éxito el 10 de noviembre de 1926 en el teatro Novedades de Madrid. España vivía bajo la dictadura conservadora y españolista de Miguel Primo de Rivera, que propiciaba la proyección, desde los estrados eruditos, de una imagen de Castilla sacrificada por causas más gloriosas que su propia existencia: España y su Imperio. Así se evidencia en una crónica firmada con las iniciales V. G. de M. que el diario madrileño $L a$ Voz publicó sobre el estreno de La pastorela, cuyo "Canto a Castilla" motivó este exaltado párrafo:

\footnotetext{
${ }^{16}$ Coro San Fernando 2001: "Los muchachos de Castilla" (Cf. Arriaca 1967: 234).

17 Coro San Fernando 2001: "Los muchachos de Castilla" (Cf. Arriaca 1967: 234).

${ }^{18}$ Marcos Redondo 1959: "Canto a Castilla" (Cf. Luque y Calonge 1927: 30).
} 
¡Castilla! ¡Madre Castilla! La que con ciega confianza prodigó su generoso esfuerzo en todas las empresas. La que con su renunciamiento se consagró a todo. ¡Castilla! Desde donde unos hombres otearon los más apartados rincones e hicieron partir las rutas que circundan el mundo por tierra y por mar. ¡Alma de Castilla! Idealismo y buen sentido, virilidad espiritual. Tiene el canto de La pastorela el poder de evocación. Recuerdo de aquellos días en que los hombres de Castilla, con la conciencia de su robustez, sintiendo como todos los fuertes ansia de dispersión, se lanzaron a dominar al mundo para gozar siempre de la lumbre del Sol, que dora las mieses en su tierra llana. Cadencia de ocaso, melancolía. Madrigal para las mozas, "que son rosa en los canchales, amapola en los trigales"; estímulo para los mozos. Noble renunciación, que renunciar es a veces conseguir más... (La Voz 11 de noviembre de 1926: 2).

Dos de los más conspicuos barítonos de aquella época (Emilio Sagi Barba —que tenía el papel de Amador en el estreno de La pastorela - y Marcos Redondo) hicieron de este tema una pieza destacada de sus repertorios, el cual se veían obligados a bisar en recitales y representaciones, prueba de lo mucho que entusiasmaba al público del momento. ¡Hasta cuatro veces hubo de repetirlo Sagi Barba en el estreno de la zarzuela en Logroño! (Heraldo de Madrid 10 de mayo de 1926: 5). Este entusiasmo queda demostrado, además, por otros dos hechos: que ambos barítonos realizaron grabaciones comerciales de la romanza en importantes casas discográficas al poco de ser estrenada (Sagi Barba, en la Compañía del Gramófono; Marcos Redondo, en Columbia), y que estas se radiaban regularmente. Pero a pesar de la notable difusión que la canción y su contenido patriótico tuvieron en el segundo cuarto del siglo XX, el "Canto a Castilla" de La pastorela quedó arrumbado en el baúl de las reliquias musicales hace ya mucho tiempo ${ }^{19}$.

No tan efusivo como esa romanza a la hora de interpretar y representar la centralidad de Castilla con respecto de España es el "Himno a Castilla" del compositor burgalés Antonio José, obra que constituye una práctica de identificación etnonacional compleja en lo que atañe a expresión y representación de la articulación entre diferentes niveles del orden patrio del autor. El 29 de junio de 1929, durante la presentación del renovado Orfeón Burgalés en las fiestas de San Pedro y San Pablo de Burgos, se estrenó esta obra coral para seis voces mixtas ${ }^{20}$ en el templete del paseo del Espolón, con letra del escritor Eduardo de Ontañón, una de cuyas estrofas dejaba clara la articulación continuista entre ambas patrias, poniendo énfasis, igual que la crónica de La Voz citada más arriba, en la proyección de Castilla no solo sobre España, sino sobre el mundo entero:

$$
\begin{aligned}
& \text { Castilla incomparable, } \\
& \text { Tú diste a España reyes, } \\
& \text { de tu virtud las leyes } \\
& \text { copiar al mundo vimos }^{21} \text {. }
\end{aligned}
$$

${ }^{19}$ Una postrera prueba de la popularización de esta canción la encontramos en una grabación de campo de unos vecinos de Gallegos de Hornija y de Vega de Valdetronco (Valladolid), realizada probablemente en 1995 y depositada en la fonoteca de la Fundación Joaquín Díaz, en la que una informante ya entrada en años canta, con variaciones en letra y en música, esta pieza entre otras tradicionales (corte 27 de la referencia 563/K de dicha fonoteca).

${ }^{20}$ A pesar de su factura académica, la popularización de este himno era un deseo del autor, según se deduce de la carta que este envió a José Subirá el 24 de noviembre de 1931 (en Palacios Garoz 2002: 176).

${ }^{21}$ Orfeón Burgalés 1977: "Himno a Castilla”. La versión que incluía esta estrofa era la que habitualmente se interpretaba hasta la década de 1980. Barriuso Gutiérrez, García Romero y Pala- 
Antonio José dejaba constancia de su categorización de ambas patrias (Castilla, "región"; España, "nación") y de su manera de articularlas (la una como parte coadyuvante de la otra) en un escrito sobre España de ese año 1929, inédito hasta 2002:

Las variedades regionales me las explico y las deseo como la amenidad y el desarrollo de un todo exuberante. Mantenerlas y hasta acentuarlas es hacer más agradable el sentido de lo estético. Pero sin desequilibrar el todo, cuyo fin es la tendencia unánime a robustecer el carácter unitario de la nación y del Estado (en Palacios Garoz 2002: 325).

Renunciaba, no obstante, al nacionalismo exacerbado porque consideraba que existe un nivel superior a todas las "naciones" que justifica una reconsideración de las consecuencias negativas que las prácticas excluyentes de identificación y diferenciación etnonacionales pueden llegar a tener:

Las nuevas corrientes nacionalistas, seguidas por una parte de la juventud actual (como la "Acción Francesa", "Casco de acero" alemana, y "Giovenezza fascista" italiana), marcan una tendencia nada tranquilizadora hacia la enemistad dentro y fuera del país donde tales corrientes de separación unitaria se efectúan. En cambio, la expansión y cultivo del bien orientado internacionalismo y del cosmopolitismo comprensivo y franco será siempre una mano fraterna y jovial tendida al deseado acercamiento universal. ¿Qué mejor Patria que una humanidad sin fronteras de amenaza, y con un mundo entero para alegría, enseñanza y propiedad suya? (ibid:: 326).

De todos modos, Antonio José no solo expresó su modelo de articulación entre Castilla y España a través de la letra del himno, pues determinadas circunstancias relacionadas con la composición y el uso del mismo sirvieron tan bien a esa expresión como pudieran hacerlo los versos cantados, que el autor cambió, por cierto, en dos ocasiones. La primera de esas variaciones se produjo al proclamarse la República en 1931, ya que el autor tenía la intención de presentar la obra a un frustrado concurso para dotar a España de un nuevo himno, pues decía estar «encariñadísimo con España y su magnífica República", según una carta suya dirigida al musicólogo José Subirá, firmada el 29 de noviembre de 1931 (ibid.: 175). De hecho, el himno había sido concebido para España antes que para Castilla, confesaba en esa epístola Antonio José (ibid:: 176). Pero el compositor también desvelaba la expresión de una triple articulación patria (Burgos-Castilla-España), pues escribía que "está inspirado en un arrogante tema de nuestros clarineros municipales burgaleses, por lo tanto con raíces castellanas; Castilla corazón de España y Burgos cabeza de Castilla" (ibid:: 176).

La versión definitiva del himno — que excluye la estrofa citada - la firmó Antonio José en 1934. El musicólogo Miguel Ángel Palacios Garoz propuso al Ayuntamiento de Burgos que elevara a la Junta de Castilla y León una proposición para que la convirtiera en el himno de la Comunidad Autónoma ${ }^{22}$. La propuesta fue aprobada por unanimidad del Pleno del Ayuntamiento en sesión ordinaria del día 28 de febrero de $2002^{23}$, pero no

cios Garoz (1980) comenzaron a desempolvar la versión que suele interpretarse hoy, sin la estrofa citada (Cf., por ejemplo, Coro de Radiotelevisión Española 1997: "Himno a Castilla").

${ }^{22}$ El himno ya había sido reivindicado como símbolo de Castilla (no de Castilla y León, a la que consideraban un ente que agrupa artificialmente una parte de Castilla con León) por los nacionalistas de la Unión Castellanista en sus cuñas radiofónicas de las elecciones de 1991.

${ }^{23}$ Formaba parte de aquel pleno Luis Marcos Naveira, concejal por Tierra Comunera-Partido Nacionalista Castellano, actualmente integrado en el PCAS. No obstante, estas agrupaciones polí- 
fue tenida en cuenta por el gobierno autonómico al no ser competente para elegir un himno oficial de la Comunidad, ya que este debería ser aprobado por una ley de las Cortes de Castilla y León. De todos modos, la proposición suscitó el recelo de los leonesistas, que mostraron su rechazo ante el Pleno de las Cortes del 6 de marzo de 2002 por medio del procurador de la Unión del Pueblo Leonés (UPL), José María Rodríguez de Francisco. La aceptación de un himno a Castilla para representar a la Comunidad Autónoma de Castilla y León supondría la identificación de esta con Castilla, y eso no iban a tolerarlo los leonesistas.

Durante la II República, momento en el que se gestó la versión definitiva del "Himno a Castilla", algunos eruditos clamaban por la desvinculación de Castilla con el centro de España ${ }^{24}$, aunque tampoco cesaban las voces que seguían apelando a la Castilla entregada por España. El 29 de octubre de 1933, una nueva organización se presentaba en el teatro de la Comedia de Madrid: Falange Española. Pocos meses después, el 4 de marzo de 1934, el teatro Calderón de Valladolid servía de escenario para la lectura del discurso de proclamación de la Falange Española y de las JONS por José Antonio Primo de Rivera, que evocaría en la cuna de su aliado Onésimo Redondo (el "Caudillo de Castilla" de la épica franquista) las eternas aspiraciones españolistas e imperialistas de Castilla y su renunciación a sí misma (Primo de Rivera 1945: 28). El discurso finalizaba con una frase que resume toda una teoría de la articulación CastillaEspaña: "Así nosotros, bajo el signo del yugo y de las flechas, venimos a decir aquí mismo, en Valladolid: ‘Castilla, otra vez por España!’” (ibid.: 36).

La ideología de José Antonio y Onésimo - entre otros - tuvo una adulterada continuidad en el partido único fundado por Franco en 1937: Falange Española y Tradicionalista de las JONS, que unificó dos tendencias difícilmente conciliables: el falangismo y el carlismo. Desde esta perspectiva política, Castilla volvía a entregarse por España en la Guerra Civil, y así lo proclamaría uno de los rapsodas del nacionalsindicalismo franquista: Federico de Urrutia. En 1938 publicaba un libro de poemas que incluía el "Romance de Castilla en armas" (Urrutia 1938: 25-30), exaltador del heró́smo de los falangistas "Castellanos" en la contienda y de su entrega por España:

¡Pero no te asustes, Madre!

¡Toda Castilla está en armas!

Madrid se ve ya muy cerca.

¿No oyes? ¡Franco! ¡Arriba España! (ibid.: 29).

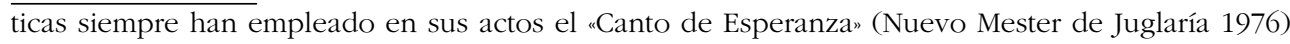
a modo de himno castellanista.

${ }^{24}$ Léase, como ejemplo, este fragmento de una crónica publicada sin firmar en el diario católico La Cruz, referida a un mitin celebrado en el teatro Pradera de Valladolid en el que intervino el historiador y político Claudio Sánchez Albornoz exponiendo sus ideas sobre la articulación de Castilla y España:

"El señor Albornoz entonó un canto a Castilla y dijo que se toma el nombre de esta región para atravesar en la vida de la República un mentido patriotismo.

Añadió que es un error pretender identificar el espíritu de Castilla con el unitarismo centralista al que se debe la verdadera desmembración del Estado español. Este no es el espíritu de Castilla. Es obra del despotismo de la Corona que arruinó a Castilla, como a las restantes regiones, y el gran error liberal del siglo diez y nueve que acogió el patrón francés de la división provincial.

No se puede consentir que tomen el nombre de Castilla para propagandas patrioteras a quienes la han explotado acaparando sus trigos" (La Cruz 19 de julio de 1932: 6). 
Bien podría parecernos este romance escrito como respuesta a ese otro que Miguel Alonso Calvo (más conocido por su pseudónimo: Ramón de Garciasol) había publicado el 5 de noviembre de 1936 en El Mono Azul, titulado "Han matado al maestro", que nos presenta una imagen miserable de la Castilla en armas del momento, totalmente opuesta a la heroica de Urrutia:

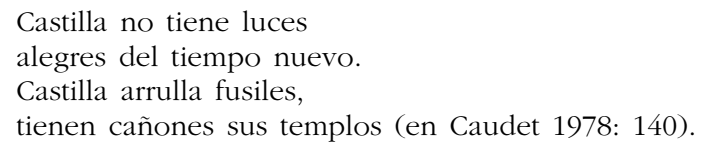

No podemos dudar, en cambio, de la influencia que el romance de Urrutia tuvo sobre una canción que, según José de Arriaca, se dio a conocer en el campamento del Frente de Juventudes de Marbella, en febrero de 1953 (Arriaca 1967: 273), pues no solo sus líneas argumentales discurren por los mismos senderos, sino que llegan a emplearse versos análogos en ambos discursos. La canción —a la que me he referido en la primera parte de este artículo- se conoce como "El Alto de los Leones", o por el íncipit de su letra: "Los muchachos de Castilla". Como ya anoté, evoca la gesta de las falanges "castellanas" por España en la batalla del Alto del León, que a partir de entonces pasaría a ser, en la toponimia franquista, el Alto de los Leones de Castilla. La versión oral de esta canción, de la cual el propio José de Arriaca desconoce autores (ibid.: 273), ha sido interpretada y grabada en estas últimas décadas por el Coro San Fernando (2001), dedicado a recuperar el corpus cancioneril del Frente de Juventudes.

Alejado del estilo épico y narrativo de la canción anterior, pero igualmente coherente con la imagen ruralista y maternal que el franquismo ofreció de Castilla (o virtuosa y paridora de España, que viene a ser lo mismo en su retórica), es otro canto que expresa en su estribillo la relación materno-filial entre ambas patrias:

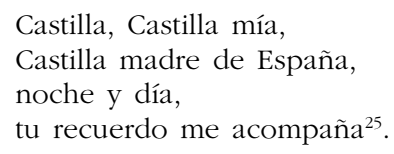

Del mismo modo que en el "Canto a Castilla" de La pastorela, la identificación total de Castilla con España se hace manifiesta en una de sus coplas:

Espuma caliente de mies amarilla,

le dicen amores al viento al pasar,

y se oye en el viento la voz de Castilla,

que es la voz de España puesta en un $\operatorname{altar}^{26}$.

Lola Flores interpretó este canto a Castilla en la película Un alto en el camino, dirigida por Julián Torremocha y producida por Cifesa en 1941. Se trata de la adaptación cinematográfica de una obra teatral del mismo título escrita por Julián Sánchez

\footnotetext{
${ }^{25}$ Según la versión cantada por Lola Flores en la película Un alto en el camino, dirigida por Julián Torremocha en 1941 (Cifesa).

${ }^{26}$ Ver nota anterior.
} 
Prieto, "El Pastor Poeta" (1928). Los dípticos publicitarios que se entregaban entonces en los cines anunciaban la película como una "loa en honor del campo y el campesino español" (fig. 2).

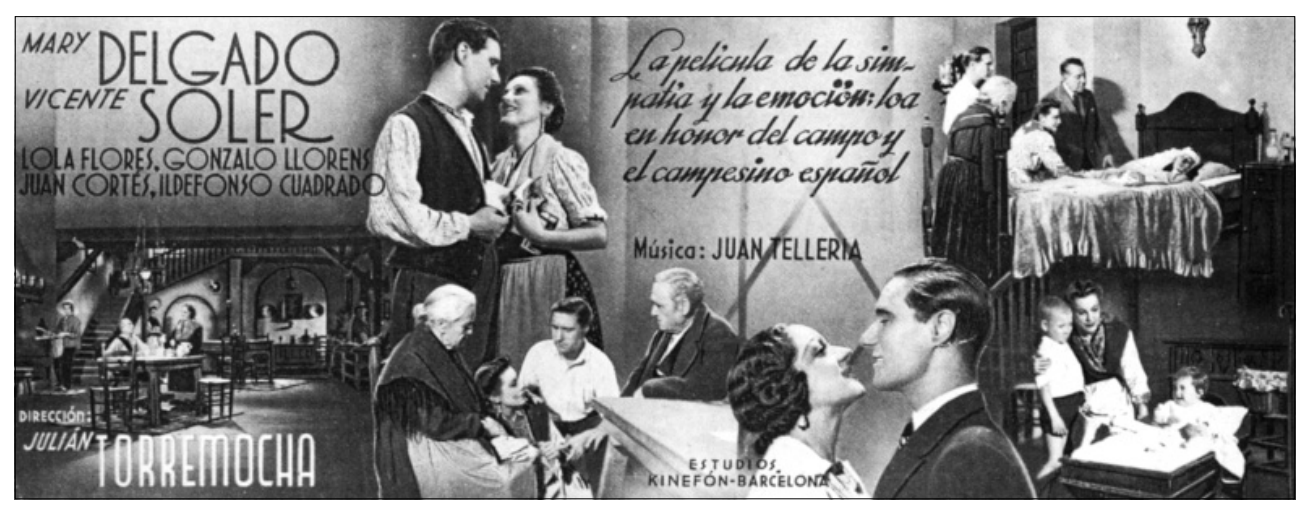

Figura 2.-Propaganda de la película Un alto en el camino, de Julián Torremocha.

Lo cierto es que la obra teatral y la adaptación cinematográfica son sendas apologías de los estereotipos axiológicos de Castilla y del campesino "castellano" (acechado por los contravalores provenientes de la ciudad); pero lo más probable es que, para quien redactó la citada propaganda, aquellos tópicos fueran los mismos que los de España y los del campesino "español". En la película, este canto con aire de jota (que "La Faraona" interpreta bajo el personaje de Soledad Molina en el teatro de Talavera un día de feria ganadera) resume en dos coplas y un estribillo ese ideario de Castilla.

La autoría de la canción no queda clara, pues aunque el compositor de la música de la película está acreditado (Juan Tellería ${ }^{27}$, bien conocido por ser el autor de la música del himno falangista "Cara al sol»), ni la letra forma parte de la obra original de "El Pastor Poeta" (Cf. Sánchez Prieto 1928), ni el letrista es nombrado en los créditos del film ${ }^{28}$. Las versiones populares que se cantan actualmente presentan ligeras variaciones en música y letra con respecto a la de la película, e incluyen más estrofas. Algunas de ellas inciden en la identificación de "castellano" con "español»:

Su gente de campo, de cara morena, tiene la bravura del pueblo español, porque en su llanura de calma serena se dieron un beso la tierra y el sol'29.

${ }^{27}$ No obstante los créditos de la película, que solo nombran a Juan Tellería como autor, Belén Pérez Castillo cataloga la banda sonora de Un alto en el camino (con referencia SGAE 2544773) como realizada en colaboración con Ángel Zapata González (Pérez Castillo 1996: 69).

${ }^{28}$ Tampoco aclaran este punto Belén Pérez Castillo (1996: 69) o Ángel Luis Hueso (1998: 38).

${ }^{29}$ Según la versión del grupo Trigo Verde, de la Casa de Castilla y León en la Sierra (Collado Villalba) (Cf., por ejemplo, la versión propuesta por Dionisio Pomar Gómez en Vázquez [2006: 22]). 
Por lo que me cuentan algunos de mis informantes ${ }^{30}$, parece claro que ciertos colegios religiosos, entre ellos el de los Padres Salesianos de Madrid, tuvieron bastante que ver en la popularización de esta canción, ya que formaba parte del repertorio que enseñaban a sus alumnos ${ }^{31}$, al menos entre los años 50 y 80 del siglo XX. Uno de estos informantes es Abdón Curto, responsable de que la canción se escuche frecuentemente en los conciertos de corales de la actual Comunidad Autónoma de Castilla y León:

Yo me eduqué en un colegio salesiano, donde el teatro y la música se cuidaban mucho. Pero como era colegio de curas, estaban prohibidas todas las canciones de temas amorosos, así que cantábamos cantos folclóricos, a las madres, a la naturaleza... y entre ellos, aprendimos este "Canto a Castilla". Años después se lo ó cantando en televisión nada menos que a Lola Flores. Me animé a armonizarla como un gesto sentimental a mis primeros recuerdos musicales (comunicación escrita de Abdón Curto con el autor, 10 de junio de 2011).

El arreglo para cuatro voces mixtas que hizo del tema original fue muy bien recibido, desde la última década del pasado siglo, por muchas agrupaciones corales (La Moraña —que lo estrenó-, Coral Castilla, Coral Castilla Vieja, Coral Carrionesa...). Algunas de ellas, como las corales Voces Amigas, La Cotarra o Blanca de Castilla, lo han grabado en cedés comerciales de escasa difusión.

Y del mismo modo que sucediera con el "Himno a Castilla" de Antonio José, no falta quien quiere ver en este canto el himno idóneo para la Comunidad Autónoma de Castilla y León (Cf. Vázquez 2006: 22; García Paredes 2006: 6), provocando las previsibles críticas basadas en la falta de representación de León en la canción (Cf. Delgado García 2006: 19).

\section{"CASTILLA NO ES EL CENTRO"}

Hemos visto que la identificación de Castilla con el centro de España ya fue rechazada por intelectuales republicanos, aunque habrá que esperar el ocaso de la dictadura de Franco para escuchar canciones que maticen la proposición Castilla ha becho España y que, sobre todo, nieguen su corolario Castilla es el centro de España. Grupos y solistas pertenecientes a los movimientos musicales comercialmente conocidos como "canción de autor" y "música folk" — difícilmente discernibles en aquella época- se encargarían de componerlas e interpretarlas basándose en las tesis que intelectuales como Claudio Sánchez Albornoz, Julio Valdeón, Julián Marías y otros pregonaban por esas fechas en artículos periodísticos, ensayos históricos o actos políticos.

${ }^{30}$ Aparte del registro en el cuaderno de campo de segmentos de discurso producidos por los sujetos en sus interacciones (conmigo y entre ellos) durante la observación participante, en el transcurso de mi trabajo de campo obtuve más información mediante entrevistas orales y escritas a numerosos sujetos relacionados con la música y la danza, la investigación etnográfica, la educación escolar, la política y las administraciones locales. Las entrevistas orales siguieron un guion más bien abierto, mientras que las escritas planteaban preguntas concretas sobre cuestiones puntuales.

${ }^{31}$ Aparte de Abdón Curto, a quien cito más abajo, también me proporcionó información interesante sobre este punto Gonzalo Ortega Aragón, que había publicado una columna sobre este canto en Diario Palentino (2011: 56). 
Uno de esos grupos fue Orégano, que comenzaría su andadura en 1976. En 1977, empezaron a cantar una composición propia que no grabaron hasta 1989: "Somos castellanos". En ella reivindicaban una Castilla no identificada con el centro:

Castilla no es la siega, ni los prados, ni los campos.

Castilla no es el centro, ni es el trigo, ni el manzano.

Castilla son los hombres, los hombres castellanos ${ }^{32}$.

Y como "hombres castellanos" querían dejar claro que:

No somos un pueblo que oprime: solo oprimen los tiranos

y los tiranos son pocos; son muchos los hermanos

de otras tierras que luchan, de otros países de al lado ${ }^{33}$.

El siguiente párrafo, que uno de los componentes del grupo (el periodista Álex Grijelmo) escribía para explicar la "lucha por la supervivencia" de Castilla (Grijelmo 1986: 9), bien puede extractarse de su contexto original para servir de exposición de motivos de esta canción:

Con la nueva España de las autonomías, Castilla buceó en sus raíces para reencontrar una identidad mediante la cual defenderse de tantas agresiones políticas. Se la había acusado de centralista, de constituir el poder que había sojuzgado a las demás comunidades, de imponer su idioma y su cultura. Los jóvenes castellanos no conocían apenas su propia historia, acostumbrados como estaban a que se identificase la historia de Castilla con la historia de España. Y cuando la encontraron pudieron comprobar que la primera revolución moderna se produjo en sus tierras y concluyó en Villalar un 23 de abril de 1521, con la derrota ante las tropas del rey don Carlos y la ejecución de los capitanes comuneros Juan Bravo, Francisco Maldonado y Juan de Padilla. Vieron también que Castilla había ido perdiendo su identidad y que el centralismo, con el que no tuvo nada que ver, se había empleado en su contra (ibid:: 9-10).

A este centralismo españolista se le vieron, en los años de la Transición, soluciones federales y autonómicas que fueron pregonadas desde los escenarios y las emisoras de radio por grupos musicales "Castellanos", alguno de los cuales llegó a tener una importante difusión comercial. Es el caso de La Fanega, un conjunto de jóvenes estudiantes de Valladolid que no faltaba a la cita de los primeros "Villalares" para pedir a ritmo de jota un Estatuto de Autonomía para León y Castilla. La canción, titulada "Una jota castellana", decía de este modo:

Trabajando para otros
nos hemos pasao la vida
todo impuesto desde arriba
queremos un estatuto
para León y Castilla ${ }^{34}$.

32 Orégano 1989: "Somos castellanos". El fragmento de la canción correspondiente a esta estrofa fue empleado como broche de la cuña electoral de Unión Castellanista citada más arriba (ver nota 22).

${ }^{33} \mathrm{Ibid}$. En los años de la fiebre autonomista, circuló una pegatina que reelaboraba, desde la simbología castellanista, la famosa fotografía de Joe Rosenthal "Raising the Flag on Iwo Jima". Los soldados estadounidenses habían sido sustituidos por paisanos castellanos, y la bandera de los Estados Unidos, por un pendón castellano. Sobre el dibujo se leía: "No somos un pueblo que oprime / Solo oprimen los tiranos / ¡SOMOS CASTELLANOS!”.

${ }^{34}$ La Fanega 1977: “Una jota castellana”. 
Victimismo más petición de autogobierno: una fórmula que se repetía en "Pueblo comunero", de Nemesio Velasco "Nes", que sus conciudadanos del grupo Madrigal (Palencia) grabaron en su primer single:

Agrupémonos en torno a nuestra tierra,

y elijamos el pendón como insignia regional.

A luchar, a luchar por nuestro pueblo,

que proclama autonomía en un estado federal.

Tú eres altiva y debes luchar;

Castilla se muere en su soledad.

Tú eres altiva y debes luchar;

Castilla no debe ser víctima más ${ }^{35}$.

\title{
"CASTILla NO HIZO ESPAÑA"
}

En aquel momento trascendental de cambio político en España, tampoco faltaron cantautores que negaran abiertamente cualquier relación de continuidad entre Castilla y España, como Elisa Serna. En 1972, grababa en Francia la canción "Áspera Meseta" (huelga decir que Meseta es un tropo de Castilla). Se trata de una temprana canción contra la imagen de una Castilla centralista y opresora que, si bien parece reconocer su ansia expansionista, señala a Caín ("el centralismo borbónico-falangista" al que se refiere Andrés Sorel en la presentación de la carpeta del disco) como culpable de ella:

\author{
Áspera Meseta, \\ No te quieras ensanchar \\ Por más que plantes banderas \\ Nunca llegarás al mar. \\ Áspera Meseta, \\ No eres tú, sino Caín \\ El que quiere que Madrid \\ Siga dictando los fueros \\ Catalán, Vasco y Gallego ${ }^{36}$.
}

Pero al retomar el tema en 1978, hará más explícita su forma de entender la articulación de ambas patrias, negando sin ambages que Castilla hiciera España en "Regreso a la semillan:
Ronca suena la dulzaina, de tanto querer gritar:
Que Castilla no hizo España
(que perdió en Villalar)
pongo sus campos resecos
en prueba de honestidad ${ }^{37}$.

\footnotetext{
35 Madrigal 1978: "Pueblo comunero".

${ }^{36}$ Elisa Serna 1972: "Áspera Meseta".

${ }^{37}$ Elisa Serna 1978: "Regreso a la semilla".
} 
Las voces que desde Castilla matizaban o negaban un modelo continuista de articulación entre la patria "castellana" y la "española" eran apoyadas por otras provenientes de fuera. Así, también en 1978, el cantautor nacionalista "valenciano" Lluís el Sifoner grababa "No tinc res contra Castella", que no solo disculpaba a Castilla de toda acusación relacionada con la opresión centralista, sino que la situaba en el mismo saco de las patrias que, como la suya, la sufrían:

\author{
No tinc res contra Castella \\ contra el poble castellà \\ que l'enemic és comú \\ i hem d'anar junts a lluitar ${ }^{38}$.
}

No obstante, la identificación de Castilla con España o con su centro, entendido este como un opresor de los pueblos periféricos, no fue una idea fácilmente desechable, como lo demuestra "Dios te llibre de Castiella" (grabada originalmente por Nuberu en 1980 en su disco Atiendi, Asturies, editado por Movieplay), que el público no ha dejado de corear en los conciertos del grupo. Tras un breve resumen de la historia de Asturias que pone todo el énfasis en su lucha por la libertad, la canción termina con una copla tajante:

Per eso Asturies del alma
el pasau nun lu escaezas
y si lu escaeces un día:
Dios te llibre de Castiella!!!39

El 7 de septiembre de 2002, durante los actos del Día de Asturias, se organizó un concierto en Oviedo en el que participaron figuras destacadas de la música de esa Comunidad, y que fue registrado en un cedé producido por el Gobierno del Principado (Varios intérpretes 2002). No faltó a la cita Nuberu con "Dios te llibre de Castiella", cuya interpretación ocupa una pista de siete minutos en la grabación. De ellos, cuatro corresponden a la repetición insistente del verso que da título a la canción: hasta nueve veces, de las cuales dos se entonan sin acompañamiento musical, incitando al público a corear al cantante. No obstante, a pesar de la contundencia e insistencia del verso final, Chus Pedro, cantante del grupo, me explicaba así el sentido de la canción:

En los años de la transición política en España, mediados de la década de los 70, existe una efervescencia en el concierto de las llamadas regiones y naciones del estado español, reivindicando sus señas de identidad. Nosotros que pertenecemos a esa generación de la transición y que teníamos hambre de libertad e identidad, no podíamos ser menos.

El poeta y amigo Manuel Asur parió la letra y Nuberu le puso música y voz a "Dios te llibre de Castiellaw. Era un canto en contra del centralismo político, económico y cultural. Nunca fue nuestra intención herir la sensibilidad de los castellanos porque, al igual que Asturias, Castilla en la historia contemporánea todos sabemos que sufrió un tremendo castigo (comunicación escrita de Chus Pedro con el autor, 3 de marzo de 2009).

Actualmente, el rechazo más radical a cualquier modelo continuista de articulación entre Castilla y España se produce desde las filas de simpatizantes y militantes

\footnotetext{
${ }^{38}$ Lluís el Sifoner 1978: "No tinc res contra Castella".

39 Varios intérpretes 2002: "Dios te llibre de Castiella".
} 
del "movimiento popular castellano". La aparición de la Unidad Popular Castellana (UPC, inscrita en el Registro de Partidos Políticos del Ministerio del Interior el 22 de marzo de 1983) y, sobre todo, de IzCa (registrada el 7 de enero de 2000, en la que se integró la UPC), formalizó un nuevo castellanismo de izquierdas, soberanista e internacionalista. La expresión musical de su ideología, como ocurre con otros movimientos similares en todo el mundo, se viene realizando a través de grupos adscritos a estilos como el oi!, el punk, el hard rock o el ska. Algunos de estos grupos también abordan el tema de la articulación entre Castilla y España, a la que ellos prefieren llamar "estado español" para presentarla como una simple estructura "artificial" de poder.

En la primera parte de este artículo, veíamos cómo el grupo Duff Hooligans renegaba de cualquier españolidad en su canción "Castilla comunera", que primero apareció en un cedé recopilatorio de grupos antifascistas (Varios intérpretes 2005) producido y distribuido por las Juventudes Castellanas Revolucionarias (JCR, reorganizadas después como Yesca, agrupación juvenil vinculada a IzCa), y dos años más tarde en su cedé Los elegantes chicos de la clase obrera (Duff Hooligans 2007).

Pero no es el único ejemplo de canción que propone, desde ese complejo entramado de declaraciones categoriales ("castellano", "joven", "obrero" y "socialista"), un modelo rupturista radical de articulación entre Castilla y España. "Lengua de libertad", del grupo Diablo Cojuelo — también vinculado a IzCa y a Yesca- lo hará abordando uno de los rasgos culturales que más preocupa - y más problemas de caracterización etnonacional presenta - a quienes trabajan por la construcción de la «identidad castellana" desde las esferas políticas y académicas (Cf., por ejemplo, Díaz Viana 1997: 41-43; 2010: 54-56):

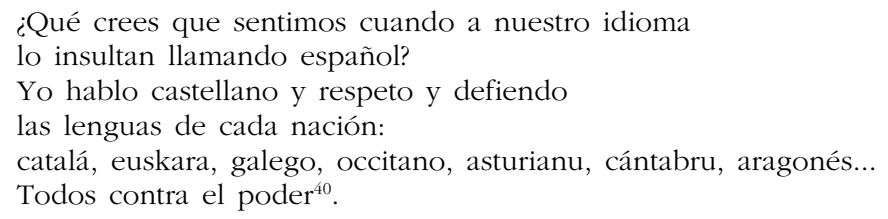

El tema de la lengua no era nuevo en el discurso de Diablo Cojuelo. En 2007, el grupo había editado una maqueta en la que incluía "Despierta", canción de la que Comuner@s (partido político inscrito el 17 de enero de 2008 en el Ministerio del Interior como una nueva y efímera marca del castellanismo soberanista de IzCa para concurrir a las Elecciones Generales de 2008) utilizaría un fragmento para ambientar las cuñas radiofónicas de su propaganda electoral. La introducción de la canción está compuesta por testimonios hablados de reivindicativo contenido castellanista sobre una base musical, el primero de los cuales dice:

El hecho de que nuestro idioma pase a llamarse idioma español en vez de idioma castellano tiene un componente político muy importante, y es el hecho de arrebatarnos a nosotros uno de nuestros patrimonios culturales fundamentales, que es el idioma ${ }^{41}$.

\footnotetext{
${ }^{40}$ Diablo Cojuelo 2008: "Lengua de libertad".

41 "Despierta" en http://es.myspace.com/diablocojueloska. (Última consulta 4 de octubre de 2013 ).
} 


\section{CONCLUSIÓN}

Aunque actualmente no existe ningún ente político y/o administrativo dotado de territorio que se llame meramente Castilla, muchos agentes sociales siguen conformando, con sus prácticas de identificación y diferenciación, una patria que denominan así: una comunidad, un tiempo y un espacio caracterizados en su acción social como "castellanos" con los que establecen o no vínculos mediante predicados de origen. En esta afirmación subyacen dos ideas importantes que, aun referidas en este caso concreto a Castilla, considero válidas para cualquier patria:

La primera es que no solo quienes se identifican como "castellanos" —independientemente de que categoricen Castilla como "región" o "nación" y de que pretendan o no burocratizarla - hacen emerger dicha patria de la acción social, sino también los que se diferencian conscientemente de ellos, conformándola así como una patria ajena.

La segunda es que Castilla es un proceso abierto de esa acción dialógica de los agentes. Las propuestas de cierre semántico de tal crono-topónimo suelen ser defendidas en la práctica con tesis esencialistas que pretenden cosificar - a menudo con tropos que personifican- lo que no existe sino como una forma de la propia acción social $^{42}$. Esta clausura semántica — que no pasa de ser incoativa a pesar de haber creído encontrar las herramientas para su consecución definitiva en los modelos etnonacional de identificación y estatal de burocratización- conlleva un intenso debate erudito sobre la imaginada esencia de Castilla, que afecta, principalmente, a límites espaciotemporales y socioculturales, pero también a su articulación con otras patrias.

Respecto a este punto, uno de los temas que siguen candentes en los discursos de los agentes es la relación de Castilla con España. Desde los años veinte del siglo XIX, historiadores, literatos y otros intelectuales, junto a políticos que en ocasiones también pertenecían a las anteriores categorías, han venido afirmando, matizando o negando la centralidad e, incluso, la "maternidad" de la primera con respecto de la segunda mediante argumentos que han fluido hacia discursos no académicos. No cabe la menor duda de que la presencia de tales líneas argumentales en canciones populares y popularizadas también ha contribuido, de algún modo, a ese flujo de ideas desde la intelectualidad hacia los agentes menos eruditos, y al anclaje de las mismas en los discursos de identificación patria de estos últimos.

\section{DISCOGRAFÍA CITADA}

Coro de Radiotelevisión Española (Director: Marcos Vega). 1997. Antonio José. Integral de su música para coro. Madrid: Radiotelevisión Española. 25094.

[Coro San Fernando]. 2001. Cancionero inédito del Frente de Juventudes. Madrid: Documedia. PARCCD260921.

Diablo Cojuelo. 2008. Continuar. Valladolid: AutoEditados Distro. AE 08-22.

Duff Hooligans. 2007. Los elegantes chicos de la clase obrera. Madrid: Working Class Records. WCR036. Elisa Serna. [1972]. Quejido. Francia [sin ciudad]: Le Chant du Monde. GU LDX 74511.

\footnotetext{
${ }^{42}$ Ángel Díaz de Rada (2010) ha empleado antes que yo este argumento - tan alejado del esencialismo como del artificialismo- para analizar el concepto de cultura.
} 
Elisa Serna. 1978. Regreso a la semilla. [Barcelona]: Edigsa. EDX 73311.

La Fanega. 1977. Y cada paso que demos... Madrid: Movieplay. 17.1209/5.

Lluís el Sifoner. 1978. La mare que els ha parit. Madrid: Movieplay. 17.1425/3.

Madrigal. 1978. Pueblo comunero. Cantar es denunciar. Madrid: Zafiro. NOX-330.

Marcos Redondo. 1959. El arte de Marcos Redondo. Barcelona: EMI-Odeón. MOAL 110.

Nuevo Mester de Juglaría. 1976 [Edición en CD de 1989]. Los comuneros. Madrid: Polygram Ibérica. 838 382-2.

Orégano. 1989. Otra vez pasan los árboles. Madrid: Saga. SPD-10019.

Orfeón Burgalés (Director: Salvador Vega). 1977. Canción burgalesa. Madrid: Audio \& Vídeo S.A. CAB-10.013.

Varios intérpretes. 2002. Concierto de Asturias. Oviedo: Fono Astur. FACD 87121.

Varios intérpretes. 2005. Miles de voces, una misma lucha. Solidaridad antifascista. [Valladolid]: Xtrañas Grabaciones. [Sin referencia].

\section{BIBLIOGRAFÍA CITADA}

Arriaca, J. de. 1967. Cancionero de juventudes. Madrid: Doncel.

Barriuso Gutiérrez, J.; García Romero, F. y Palacios Garoz, M. A. 1980. Antonio José. Músico de Castilla. Madrid: Unión Musical Española.

Barth, F. (comp.). 1976 [1969]. Los grupos étnicos y sus fronteras. La organización social de las diferencias culturales. México: FCE.

Baumann, G. y Gingrich, A. (ed.). 2004. Grammars of Identity/Alterity. A Structural Approach. New York: Berghahn Books.

Caudet, F. (ed.). 1978. Romancero de la guerra civil. Madrid: Ediciones de la Torre.

Delgado García, E. 2006. "Otro himno". El Norte de Castilla [Valladolid, Palencia y Segovia] 4 de agosto: 19. Opinión. Cartas al director.

Díaz de Rada, A. 2008. "¿Dónde está la frontera? Prejuicios de campo y problemas de escala en la estructuración étnica en Sápmi». Revista de Dialectología y Tradiciones Populares LXIII (1): 187235.

Díaz de Rada, A. 2010. Cultura, antropología y otras tonterías. Madrid: Trotta.

Díaz Viana, L. 1997. Castilla y León. Imágenes de una identidad. Notas para un manual de etnografía. Valladolid: Ámbito.

Díaz Viana, L. 2010. "Castilla y León, un territorio cuestionado: Retóricas del espacio y del tiempo en la construcción de identidades". Revista de Dialectología y Tradiciones Populares LXV (1): 45-64.

García Paredes, R. 2006. "Otro himno". El Norte de Castilla [edición de Valladolid] 20 de julio: 6. Valladolid. La voz del lector.

González Lucini, F. 1989 [1984]. Veinte años de canción en España (1963-1983) 1. De la esperanza/apéndices. Madrid: Ediciones de la Torre.

Grijelmo, A. 1986. Descubra España paso a paso. Castilla y León (I). Madrid: Club Internacional del Libro.

Heraldo de Madrid 10 de mayo de 1927: 5. Teatros y cines. Los espectáculos de esta noche. "La Pastorela" en Logroño.

Hueso, A. L. 1998. Catálogo del cine español. Películas de ficción, 1941-1950. Madrid: CátedraFilmoteca Española.

La Cruz [Tarragona] 19 de julio de 1932: 6. Conferencias telegráficas. "En un mitin radical-socialista se vitorea a Cataluña".

La Voz [Madrid] 11 de noviembre de 1926: 2. Información teatral. Los estrenos de anoche. En Novedades. "La Pastorela".

López Álvarez, L. 1972. Los comuneros. Madrid: Cuadernos para el Diálogo.

Luque, F. y Calonge, E. 1927. "La pastorela". Comedias XLVIII: 1-45.

Maragall, J. 1984. Obra poética. Versión bilingüe II. Madrid: Castalia.

Marías, J. 1977. La devolución de España. Madrid: Espasa-Calpe. 
Ortega Aragón, G. 2011. "Himno a Castilla la muy Vieja”. Diario Palentino 20 de mayo: 56. Opinión. Solana palentina.

Ortega y Gasset, J. 1977 [1921]. España invertebrada. Madrid: Espasa-Calpe.

Palacios Garoz, M. A. 2002. En tinta roja. Cartas y otros escritos de Antonio José. Burgos: Ayuntamiento de Burgos-Instituto Municipal de Cultura.

Pérez Castillo, B. 1996. "Catálogo de la obra musical de Juan Tellería Arrizabalaga". Cuadernos de Música Iberoamericana 1: 63-69.

Primo de Rivera, J. A. 1945. Obras completas. Madrid: Ediciones de la Vicesecretaría de Educación Popular de FET y de las JONS.

Sánchez Albornoz, C. 1977 [1973]. El drama de la formación de España y los españoles. Otra nueva aventura política. Barcelona: Edasha.

Sánchez Prieto, J. 1928. Un alto en el camino. Madrid: Sociedad de Autores Españoles.

Unamuno, M. de. 1986 [1902]. En torno al casticismo. Madrid: Alianza.

Urrutia, F. de. 1938. Poemas de la Falange eterna. [Sin editorial. Impreso en Santander por Aldus S.A. de Artes Gráficas].

Vázquez, M. 2006. "Dionisio Pomar Gómez, jubilado y promotor de un himno regional". El Norte de Castilla [Valladolid, Palencia y Segovia] 9 de julio: 22. Castilla y León.

Fecha de recepción: 12 de febrero de 2013

Fecha de aceptación: 2 de octubre de 2013 